\section{SAT0647 PREDICTIVE FACTORS OF POSITIVE POSITRON EMISSION TOMOGRAPHY FOR DIAGNOSING AORTITIS IN PATIENTS WITH POLYMYALGIC SYNDROME}

D. Prieto-Peña ${ }^{1,1}$, J. Loricera ${ }^{1}$, I. Martínez-Rodríguez ${ }^{2}$, J. Banzo ${ }^{2}$, M. Calderón-

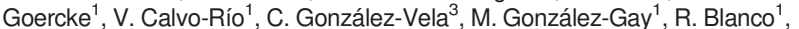
J. Hernández ${ }^{4}$. ${ }^{1}$ heumatology; ${ }^{2}$ Nuclear Medicine; ${ }^{3}$ Pathology, ${ }^{4}$ Internal Medicine, Hospital Universitario Marqués de Valdecilla, IDIVAL, Santander, Spain

Background: Isolated non-infectious aortitis is a potentially serious condition whose diagnosis is often delayed due to the non-specific nature of its symptoms. Most of the patients initially present with polymyalgic syndrome associated with atypical symptoms. Nowadays, ${ }^{18} \mathrm{~F}$-FDG PET/CT scan is the best tool for early detection of aortitis. However, it is a complex and expensive technique. Thus, we should make an effort to select those patients who will benefit the most from this procedure. Unfortunately, we have no data about which factors may improve the probability of a positive diagnosis of aortitis using this imaging technique.

Objectives: Our aim was to evaluate, in patients with polymyalgia rheumatica (PMR), the predictive factors for a positive ${ }^{18} \mathrm{~F}$-FDG PET/CT scan, in order to make an early diagnosis of aortitis and optimise the use of this technique.

Methods: Retrospective study on 97 patients with PMR who had undergone an ${ }^{18}$ F-FDG PET/CT scan between January 2010 and August 2017 with a high clinical suspicion of aortitis. Only patients with polymyalgic syndrome without any other underlying disease were included. We considered two groups: a) Classic PMR: patients who fulfilled the 2012 EULAR/ACR criteria; and b) Atypical PMR: patients with symptoms resembling PMR but did not fulfil the 2012 EULAR/ACR criteria. Distribution of categorical variables was compared by the Pearson Chi-squared test or Fisher exact test. Quantitative variables were analysed using the Student t test or MannWhitney $U$ test as appropriate. An adjusted logistic regression model was built to assess the best set of predictive factors for a positive PET scan in both groups of patients.

Results: ${ }^{18} \mathrm{~F}$-FDG PET/CT scans were performed in 97 patients due to clinical suspicion of aortitis, being positive in $60(61.9 \%)$. Patients (60 women/37 men) had a mean age of $68.4 \pm 10.7$ years. Fifty-one (52.6\%) had classic PMR and 46 (47.4\%) atypical PMR. In patients with classic PMR, the best set of predictors for a positive PET/CT scan were lower limb pain ( $\mathrm{OR}=8.4,95 \% \mathrm{Cl} 2.0-35.1 ; \mathrm{p}=0.004)$ and low back pain $(\mathrm{OR}=7.6,95 \% \mathrm{Cl} 1.3-45.5, \mathrm{p}=0.027)$, once adjusted for age, sex and current tobacco use. In atypical PMR patients, only the pelvic girdle affection (OR: $5.0,95 \% \mathrm{Cl} 1.3-19.5 ; \mathrm{p}=0.002$ ) was significantly associated with a positive $\mathrm{PET} / \mathrm{CT}$ scan, in the logistic adjusted model.

Abstract SAT0647 - Table 1

\begin{tabular}{|c|c|c|c|c|c|c|}
\hline & \multicolumn{6}{|c|}{ PMR (N=97) } \\
\hline & \multicolumn{3}{|c|}{ Classic PMR (N=51) } & \multicolumn{3}{|c|}{ Atypical PMR (N=46) } \\
\hline & $\begin{array}{l}\text { Positive } \\
\text { PEICTCT } \\
(\mathbb{N}=29) \\
\end{array}$ & \begin{tabular}{|l|} 
Negative \\
PETICT \\
$(\mathrm{N}=22)$ \\
\end{tabular} & $p$ & $\begin{array}{l}\text { Positive } \\
\text { PEIICT } \\
(\mathrm{N}=31) \\
\end{array}$ & \begin{tabular}{|l} 
Negative \\
PETTCT \\
(N=15) \\
\end{tabular} & $P$ \\
\hline Sex (women), $n(\%)$ & $20(69.0)$ & 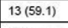 & 0.47 & $18(58.1)$ & $9(60.0)$ & 0.90 \\
\hline Age (years), mean $\pm S D$ & $72.8 \pm 8.8$ & $75.2+8.0$ & 0.32 & $62.5 \pm 9.1$ & $62.4 \pm 11.8$ & 0.97 \\
\hline \multicolumn{7}{|l|}{ Recurrence of polymyalgic symptoms } \\
\hline Neck pain, $n(\%)$ & $6(20.7)$ & $4(18.2)$ & 0.99 & $3(9.7)$ & $2(13.3)$ & 0.71 \\
\hline Shoulder girde, $n(\%)$ & $17(68.2)$ & $15(58.6)$ & 0.48 & $12(38.7)$ & $10(66.7)$ & 0.075 \\
\hline Pelvic girde, $\mathrm{n}(\%)$ & $19(65.5)$ & $11(50.0)$ & 0.27 & $20(64.5)$ & $4(26.7)$ & 0.016 \\
\hline Moming stiffness, n (\%) & $4(36.4)$ & $8(36.4)$ & 0.06 & $3(9.7)$ & $2(13.3)$ & 0.99 \\
\hline \multicolumn{7}{|l|}{ Atypical symptoms } \\
\hline Inflammatory low back pain, $n(\%)$ & $10(34.5)$ & $3(13.6)$ & 0.09 & $11(35.5)$ & $3(20.0)$ & 0.33 \\
\hline Diffuse lower limb pain, $n(\%)$ & $17(58.6)$ & $4(18.2)$ & 0.004 & $17(54.8)$ & $6(40.0)$ & 0.35 \\
\hline Asthenia, $\mathrm{n}(\%)$ & $9(31.0)$ & $6(27.3)$ & 0.77 & $3(9.7)$ & $4(26.7)$ & 0.19 \\
\hline Hyporexia, $n(\%)$ & $2(6.9)$ & $6(27.3)$ & 0.06 & $3(9.7)$ & $3(20.0)$ & 0.38 \\
\hline Weight loss, $n(\%)$ & $4(13.8)$ & $6(27.3)$ & 0.30 & 5 (16.1) & $4(26.7)$ & 0.45 \\
\hline \multicolumn{7}{|l|}{ Laboratory abnormalities } \\
\hline Anaemia, $\mathbf{n}(\%)$ & $11(37.9)$ & $12(54.5)$ & 0.24 & $8(25.8)$ & $5(33.3)$ & 0.73 \\
\hline CRP > $6 \mathrm{mg} /, \mathrm{n}(\%)$ & $3(10.3)$ & $4(18.3)$ & 0.35 & $5(16.7)$ & $2(13.3)$ & 0.77 \\
\hline$E S R>40 \mathrm{~mm}, \mathrm{n}(\%)$ & $12(41.4)$ & $12(54.5)$ & 0.57 & $16(51.6)$ & $8(53.3)$ & 0.91 \\
\hline \multicolumn{7}{|l|}{ Treatment response } \\
\hline Lack of improvement with $15 \mathrm{mg}$ of PD, $\mathrm{n}(\%)$ & $5(17.2)$ & 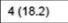 & 0.99 & $5(16.1)$ & $3(20.0)$ & 0.95 \\
\hline
\end{tabular}

Conclusions: We have found that, in patients with classic PMR, the presence of diffuse lower limb pain and inflammatory low back may have clinical relevance when requesting a PET/CT scan due to aortitis suspicion. On the other hand, in patients with atypical PMR, only the presence of pain in the pelvic girdle seems to be a predictive factor for a positive result in PET/CT scan.

Disclosure of Interest: None declared

DOI: 10.1136/annrheumdis-2018-eular.4983

\section{SAT0648}

COXALGIA IN HEMOPHILIC PATIENTS. SONOGRAPHIC EVALUATION OF A NOT TARGET JOINT

D. Melchiorre ${ }^{1}$, G. Castaman ${ }^{2}$, S. Linari ${ }^{2}$, M. Matucci-Cerinic ${ }^{1} .{ }^{1}$ Department of Experimental and Clinical Medicine, University of Florence; ${ }^{2}$ Centre for Bleeding Disorders, Azienda Ospedaliero Universitaria Careggi, Florence, Italy

Background: Background: Spontaneous bleeding in haemophilia shows a predilection for joints, and repeated hemarthrosis induce synovial inflammation, cartilage degeneration and bone damage, leading to hemophilic arthropathy. The hip is not a target joint and its involvement is not easy to be distinguished from other conditions which may provoke pain referred to the hip.

Objectives: Objectives: Aim of the study was to analyse the different sonographic findings related to different pain producing conditions.

Methods: Methods: Thirty patients with haemophilia A and monolateral coxalgia were examined. Sonographic exam (US) was performed in all patients by Esaote equipment My Lab 70 with linear probe 4-13 MHz and power Doppler. The iliopsoas muscle and its bursa, the greater trochanteric bursa, and the hip joint were analysed. Sonographic findings in the joint were scored (score ranging from 0 to 21) for effusion, bone remodelling, cartilage damage, synovial hypertrophy, hemosiderin, osteophytes, hemarthrosis, erosion and fibrotic septa. The World Federation of Haemophilia (WFH) orthopaedic joint scale score and the radiologic Pettersson score were evaluated in all patients.

Results: Results: US showed effusion in 20 hip joints $(67 \%)$, bone remodelling in $18(60 \%)$, cartilage damage in $10(33 \%)$, synovial hypertrophy in $12(40 \%)$, hemosiderin in $4(13 \%)$, osteophytes in $7(23 \%)$, hemarthrosis in $10(33 \%)$ with power Doppler activity ( $>3$ flags). In no patient erosion or fibrotic septa were observed. Fifteen out of 30 joints showed US score $\leq 5$, and 15 US score $>5$. In 8 patients a hematoma of iliopsoas muscle was present, in two patients great trochanteric bursitis was detected. WFH mean score value was 39.5 (range 12-57) and the mean Pettersson score value was 10.4 (range 6-12).

Conclusions: Conclusions: Surprisingly, in most cases (67\%) coxalgia was not related to trochanteric bursitis or iliopsoas muscle involvement but was due to hemophilic arthropathy of the hip which is not a target joint. Moreover, power Doppler allowed to detect hemarthrosis in $33 \%$ of patients, supporting the hypothesis that vascular changes and remodelling in haemophilia are associated with bleeding and joint damage ${ }^{1}$.

\section{REFERENCE:}

[1] Bhat $V$, et al. Vascular remodeling underlies rebleeding in hemophilic arthropathy. Am J Hematol 2015;90:1027-1035.

Disclosure of Interest: None declared DOI: 10.1136/annrheumdis-2018-eular.5703

\section{SAT0649 \\ CORRELATION BETWEEN CLINICAL MANIFESTATIONS AND 18F-FDG UPTAKE IN PATIENTS WITH POLYMYALGIA RHEUMATICA}

D. Prieto-Peña ${ }^{1}$, J. Loricera ${ }^{1}$, I. Martínez-Rodríguez ${ }^{2}$, J. Banzo $^{2}$, M. CalderónGoercke $^{1}$, V. Calvo-Río ${ }^{1}$, C. González-Vela ${ }^{3}$, M. González-Gay ${ }^{1}$, J. Hernández ${ }^{4}$, R. Blanco ${ }^{1} .{ }^{1}$ Rheumatology, ${ }^{2}$ Nuclear Medicine; ${ }^{3}$ Pathology; ${ }^{4}$ Internal Medicine, Hospital Universitario Marqués de Valdecilla, IDIVAL, Santander, Spain

Background: Polymyalgia rheumatica (PMR) is an inflammatory disease characterised by pain and stiffness of the neck, shoulder and pelvic girdles. It can also be accompanied by other non-specific symptoms such as inflammatory low back pain, diffuse lower limb pain and constitutional syndrome. The role of ${ }^{18} \mathrm{~F}-\mathrm{FDG}$ $\mathrm{PET} / \mathrm{CT}$ is increasing in the diagnosis of PMR but it remains unknown if there is a correlation between clinical symptoms and ${ }^{18} \mathrm{~F}-\mathrm{FDG}$ uptake.

Objectives: Our aim was to asses if the localization of pain of patients with PMR correlates with ${ }^{18} \mathrm{~F}-\mathrm{FDG}$ uptake in the corresponding region of interest.

Methods: Retrospective study of 75 patients with PMR and their respective PET/ CT scans from a referral centre. PMR diagnosis was based on 2012 EULAR/ACR criteria.

Results: We evaluated 75 patients (27 men and 48 women) with a mean age $\pm S D$ of $68.2 \pm 10.7$ years. A PET/CT was performed in all of them. Pattern of FFDG uptake in patients with different clinical manifestations were summarised in the TABLE. Twenty-two out of thirty-three patients (66.7\%) with ${ }^{18} \mathrm{~F}$-FDG uptake in sternoclavicular joints had shoulder girdle pain. In all patients with morning 